\title{
Does population have a larger impact on carbon dioxide emissions than income? Evidence from a cross-regional panel analysis in China
}

\author{
Yang Zhou ${ }^{\text {a,b,c }}$, Yansui Liu ${ }^{\text {a,b,c,* }}$ \\ a Institute of Geographic Sciences and Natural Resources Research, Chinese Academy of Sciences, Beijing 100101, China \\ ${ }^{\mathrm{b}}$ College of Resources Science and Technology, Beijing Normal University, Beijing 100875, China \\ ${ }^{\mathrm{c}}$ Key Laboratory of Regional Sustainable Development Modeling, Chinese Academy of Sciences, Beijing 100101, China
}

\section{H I G H L I G H T S}

- We reassessed the impact of demographic and GDP changes on $\mathrm{CO}_{2}$ emissions in China.

- Income rather than population growth was a major contributor to growing emissions.

- Urbanisation increases energy use and $\mathrm{CO}_{2}$ emissions, except in western China.

- Shrinking household size did not reduce energy use and emissions.

- The impact of human activities on the environment varies across regions.

\section{A R T I C L E I N F O}

\section{Article history:}

Received 22 December 2015

Received in revised form 5 August 2016

Accepted 6 August 2016

Available online 13 August 2016

\section{Keywords:}

Demographic change

Income growth

Energy use

$\mathrm{CO}_{2}$ emissions

STIRPAT model

China

\begin{abstract}
A B S T R A C T
As global warming intensifies, the accumulation of carbon dioxide $\left(\mathrm{CO}_{2}\right)$ and other greenhouse gases have attracted great global attention. However, questions regarding whether, how and to what extent demographic factors and processes affect carbon emissions have not yet been fully explained - particularly in China. This study used an improved STIRPAT model to reassess the impact of demographic and income changes on China's energy-related $\mathrm{CO}_{2}$ emissions at the national and regional levels using balanced provincial panel data from the 1990-2012 period. Whereas most previous studies of emission-popula tion/income elasticity in China have yielded wide-ranging estimates, this study showed that income rather than demographic change has been the dominant driving force behind China's growing $\mathrm{CO}_{2}$ emissions. Urbanisation has increased energy consumption and emissions, except in western China. Changes in the age structure have had a statistically insignificant effect on energy use, but resulted in increased national emissions - particularly in eastern China. Shrinking household size did not reduce energy use and emissions, indicating that improved residential energy efficiency might reduce emissions. Changing the traditional mode of economic growth, reasonable controlling the pace of urbanisation, improving energy efficiency and upgrading industrial structures may yet be necessary to mitigate the environmental impact of human activities in China.
\end{abstract}

(c) 2016 Elsevier Ltd. All rights reserved.

\section{Introduction}

Global warming is unequivocal. The average global surface temperature has increased by approximately $0.85^{\circ} \mathrm{C}$ over the 1880 2012 period [1]. Increases in anthropogenic greenhouse gas (GHG) concentrations are believed to be the dominant cause of the warming observed since the mid-20th century [1]. The primary

\footnotetext{
* Corresponding author at: Institute of Geographic Sciences and Natural Resources Research, Chinese Academy of Sciences, 11A Datun Road, Chaoyang District, Beijing 100101, China.

E-mail addresses: zhouyang@igsnrr.ac.cn (Y. Zhou), liuys@igsnrr.ac.cn (Y. Liu).
}

anthropogenic GHG is carbon dioxide $\left(\mathrm{CO}_{2}\right)$, which is predominately caused by the combustion of fossil fuels. Economic and population growth will likely continue to be the most important drivers of the increase in $\mathrm{CO}_{2}$ emissions from fossil fuel combustion [2-4]. Fully comprehending the effects of the changes in income and population on carbon emissions is important to formulate effective climate change policies/negotiations [5].

The complex mechanisms involved environmental changes and human activities have been extensively investigated in recent decades using various types of data and models, but have yielded mixed results. Among of these, the stochastic impacts by regression on population, affluence and technology (STIRPAT) model is 
a well-known method that is widely used to quantitatively assess the effects of demographic changes and economic growth on $\mathrm{CO}_{2}$ emissions. Demographic changes (including changes in population size, urbanisation, and the size and age composition of households) have implications for energy consumption and pollutant emissions patterns [6]. However, the degree to which population changes affect $\mathrm{CO}_{2}$ emissions remains the subject of debate. York et al. [7] and Cole and Neumayer [8] found that $\mathrm{CO}_{2}$ emissions respond almost proportionally to population changes at the global scale, but Shi [9] argued that population has a larger than proportional significant effect on emissions. The elasticity of populationemissions is heterogeneous at various income levels. Poumanyvong and Kaneko [10] estimated that the population- $\mathrm{CO}_{2}$ emissions elasticity for high, middle and low-income countries was 1.12 , 1.23 and 1.75 , respectively. Fan et al. [11] estimated that the population-emissions elasticities for high, upper-middle, lowermiddle and lower income countries were 0.56, 0.33, 0.44 and 0.26 , respectively. Martinez-Zarzoso and Maruotti [12] obtained a statistically insignificant population elasticity for old EU members. Slowing population growth might be response for $16-29 \%$ of the $\mathrm{CO}_{2}$ emission reductions at the global level [13]. These differences have been attributed to the different datasets used, additional variables and estimation models as well as whether and how nonstationarity and cross-sectional dependence were addressed $[5,14]$. Urbanisation is an important factor affecting energy consumption and $\mathrm{CO}_{2}$ emissions. Many studies have shown that urbanisation increases energy consumption and leads to more emissions, particularly in middle- and high-income countries [7,8,10,15-17]. Similar evidence was also obtained for OECD countries and nations in the European Union [18]. Conversely, others scholars have argued that urbanisation improves the efficient use of public infrastructures and thus lowers emissions [14,19-21]. Ponce de Leon Barido and Marshall [22] argued that the relationship between urbanisation and $\mathrm{CO}_{2}$ emissions depends on income level and environmental policy and that urbanisation decreased emissions in countries with stronger environmental policies and outcomes. Additionally, among the demographic factors, the impact of age structure and household size on $\mathrm{CO}_{2}$ emissions is another focus of academic. Working-age population (aged 15-64 years) had a negative impact on $\mathrm{CO}_{2}$ emissions in developed countries but exerted a positive impact in developing countries [11]. Liddle and Lung [20] identified a positive emissions-elasticity for young adults (aged 20-34 years) and a negative elasticity for older adults (aged 35-64 years). Household size has been shown to be negatively related to road energy use in OECD countries [14]. Jiang and Hardee [23] suggested that households should be included in any assessment of anthropogenic environmental impact.

China is undergoing a rapid demographic transition from an agricultural to an urban society, from a young society to an old one, and from a relatively stable society to a floating one [24-27]. As the world's largest energy consumer and $\mathrm{CO}_{2}$ emitter, China is now confronting the international restriction of reducing GHG emissions [27-32]. Although demographic changes may affect energy use and $\mathrm{CO}_{2}$ emissions, historical emission analyses have either omitted such demographic changes or treated them a fragmentary or overly simplified manner [13]. However, recent studies have begun to focus on the population-environment relationship in China as environmental stress has increased (Table S1, Supporting Information). Most studies show that population size and urbanisation positively associated with energy use and carbon emissions [8,10,15,33-36]. Nonetheless, scant attention has been paid to the environmental impact of age structure and household size. Notably, great changes have taken place in China's age composition and average household size since 1980. Furthermore, there are remarkable regional differences in these factors across China. Above all, many of the previous estimates regarding emission-population/income elasticity for China did not adequately consider the stationarity of the variable used, which might have result to spurious regressions, and might have yielded wide-ranging results [5,8]. Policy-makers require more detailed information about the environmental impact of human activities. Thus, it is urgent that the relationships among demographic changes, economic growth and carbon dioxide emissions are fully investigated to provide more reliable information for policymakers and urban planners in China. Using a balanced panel dataset covering 30 provinces in China over the period 1990-2012, this study applied an improved STIRPAT model to reassess the effects of population and income change on energy consumption and $\mathrm{CO}_{2}$ emissions at both the national and regional levels.

The innovation in, and contribution of, this study lies in its comprehensive assessment of the impact of population change (including population growth, migration, structure and household size) and economic growth on the environment. Based on the IPAT theoretical framework, we tried to apply the econometric model to investigate these issues regarding whether, how and to what extent demographic factors and processes as well as economic growth affect the environment. Moreover, this study tried to answer the question that demographic changes have a larger impact on the environment than income? At present, China is facing the challenges of the balancing population and economic growth, excessive consumption of resources and environmental protection. Meanwhile, China is in the rapid transition phases of population, industrial and economic structures. These findings will provide policymakers with a sound scientific basis for the rational control of population and economic growth.

\section{Theoretical framework and methodology}

\subsection{Theoretical analysis}

Fig. 1 showed the relationship between human activities and environmental impacts. Socio-economic development (including population changes, economic growth and technological improvement) inevitably increases energy consumption and emits $\mathrm{CO}_{2}$, exerting pressure on the environment $[16,27]$. Productive and living energy consumption of human society emits pollutants. To what extend demographic factors and processes affect carbon emissions depends on household size [16,37,38], population size $[5,39]$, population urbanisation level [15] and the proportion of working-age population $[20,39,40]$. In addition, economic growth tends to increase the energy consumption and lead to emit more pollutants $[17,41]$. Energy consumption is the main production factors of economic growth. Energy consumption promotes economic growth, but also inevitably emits carbon dioxide. Meanwhile, technological improvement is closely correlated to energy intensity, which the changes in the production technology can decrease the energy intensity [34].

\subsection{Methods}

The effect of human activities on the environment is mainly postulated in the IPAT model ( $\mathrm{I}=\mathrm{PAT})$, which is firstly proposed by Ehrlich and Holdren [42]. The IPAT equation specifies the anthropogenic environmental impacts $(I)$ as a function of population $(P)$, affluence and technology. The IPAT model is limited because it analyzes a problem by changing a factor while keeping others constant, resulting in proportionate impacts on the dependent variable $[9,43]$. To overcome these weaknesses, Dietz and Rosa [43] reformulated the IPAT model into a stochastic model (STIRPAT), which can statistically assess non-monotonic or nonproportional impacts of driving forces on the environment. The 


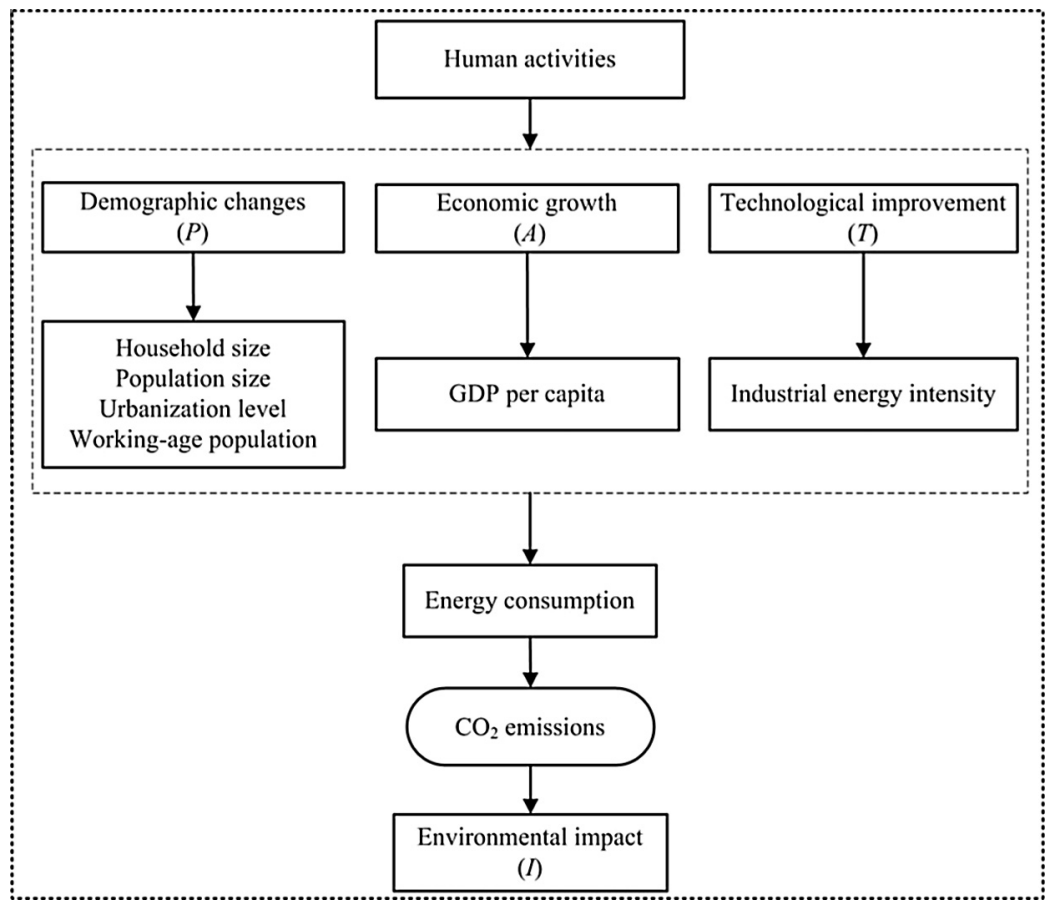

Fig. 1. Demographic changes, economic growth, technological improvement and environmental impact.

STIRPAT model has been successfully utilized to analyze the effects of driving forces on various environmental impacts $[7,10,17,27,33,35]$. The STIRPAT model can be given as following equation:

$I_{i t}=\alpha P_{i t}^{\mathrm{b}} A_{i t}^{\mathrm{c}} T_{i t}^{d} \varepsilon_{i t}$

After taking logarithms, the model takes the following form:

$\operatorname{Ln}\left(I_{i t}\right)=a+b \operatorname{Ln}\left(P_{\mathrm{it}}\right)+c \operatorname{Ln}\left(A_{i t}\right)+d \operatorname{Ln}\left(T_{i t}\right)+\varepsilon_{i t}$

here, suffixes $i$ and $t$ are provinces and years, respectively; $P$ is population size; $A$ is real GDP per capita; $T$ is technology; and the dependent variable $I$ is environmental impact; $\varepsilon_{i}$ is the error term, $a$ is the constant term; $b, c$ and $d$ are, respectively, the coefficients of $P, A$ and $T$.

The STIRPAT model allows other factors to be added to explore their effects on environmental parameters. In the STIRPAT model, factors $P$ and $A$ are decomposable, as is $T$ [7]. To fully examine the impact of population and income on energy consumption and $\mathrm{CO}_{2}$ emissions in China, urbanisation, age structure and household size were incorporated into the STIRPAT model. Following the study of York et al. [7] in this study, technology improvement was measured by the share of the added values of industry sector in the real GDP and industrial energy intensity. The extended STIRPAT model was changed as follows:

$$
\begin{aligned}
\operatorname{Ln}\left(\mathrm{EC}_{i t}\right)= & a_{0}+a_{1} \operatorname{Ln}\left(\mathrm{POP}_{i t}\right)+a_{2} \operatorname{Ln}\left(\mathrm{URBA}_{i t}\right)+a_{3} \operatorname{Ln}\left(\mathrm{WAP}_{i t}\right) \\
& +a_{4} \operatorname{Ln}\left(\mathrm{HS}_{i t}\right)+a_{5} \operatorname{Ln}\left(\mathrm{pGDP}_{i t}\right)+a_{6} \operatorname{Ln}\left(\mathrm{INDU}_{i t}\right)+\varepsilon_{1 i t} \\
\operatorname{Ln}\left(\mathrm{CO}_{2 i t}\right)= & b_{0}+b_{1} \operatorname{Ln}\left(\mathrm{POP}_{i t}\right)+b_{2} \operatorname{Ln}\left(\mathrm{URBA}_{i t}\right)+b_{3} \operatorname{Ln}\left(\mathrm{WAP}_{i t}\right)+b_{4} \operatorname{Ln}\left(\mathrm{HS}_{i t}\right) \\
& +b_{5} \operatorname{Ln}\left(\mathrm{pGDP}_{i t}\right)+b_{6} \operatorname{Ln}\left(\mathrm{INDU}_{i t}\right)+b_{7} \operatorname{Ln}\left(\mathrm{EI}_{i t}\right)+\varepsilon_{2 i t}
\end{aligned}
$$

where POP is the total population; URBA is the urbanisation level; WAP is the share of the working-age population (16-64 years old); HS is the average household size; pGDP is the real per capita GDP; INDU is the share of the added values of industry sector in the GDP; EI is the industry energy intensity (expressed as industry energy use per unit industrial added value); $\mathrm{EC}$ and $\mathrm{CO}_{2}$ denote the total energy and $\mathrm{CO}_{2}$ emissions, respectively. The energy intensity is included in only the emission models because it contains part of the dependent variable.

Two steps were performed to examine the impacts of demographic changes and income growth on energy consumption and $\mathrm{CO}_{2}$ emissions for the entirety of China and for the three regions (i.e., eastern, central and western China) [27]. First, the presence of unit roots in the all variables was verified before proceeding to any econometric analysis [44-46]. The Pesaran CIPS test [47], as one of the second-generation panel unit root tests, was performed to test the stationary of the all variables. The results of that test suggested that many variables are non-stationary in their levels, but most of them become stationary at the $5 \%$ significance level after taking first differences, which indicates that the variables in all panels are integrated of order one or I(1) (see Table S2). Second, the impact of demographic changes on energy use and carbon emissions for the whole sample and the three regions were estimated using four methods: ordinary least square (OLS), feasible generalized least squares (FGLS), fixed effects (FE) and first differenced (FD), generating thirty-two models. Specifically, the FGLS was applied to address the autocorrelation and cross-sectional dependence. However, the method is cannot be used only the time dimension is at least as big as the cross-sectional dimension. The FGLS standard errors would underestimate true variability [15]. To address these problems, the FE estimation was used to alleviate heterogeneity bias. The autocorrelation in the fixed effect models was verified by the Wooldridge test and the autocorrelation in the fixed effect models was found [48]. Moreover, we confirmed the presence of groupwise heteroskedasticity in the all modes using the modified Wald statistic [49]. We also detected the existence of cross-sectional dependence by Pesaran test in the fixed effect models [50]. Consequently, the results of the FE estimation could possibly be biased [51]. To address those issues, the FD estimation is employed, which can address properly the important econometric concerns including cross-sectional dependence, heteroskedasticity and nonstationarity, which has been widely used to assess the impact of human activity on the environment $[8,10,12,16,18]$. Because the FD model was robust to cross-sectional 
dependence and stationary, the interpretations of this study focused only on the results of the FD estimates. Additionally, the multicollinearity among the explanatory variables in the FD models was tested by the variance inflation factors (VIF). The VIF values are all less than 10, indicating no multicollinearity (see Table S3).

\section{Data description}

\subsection{Data sources}

This study used a balanced panel dataset of 30 provinces in China over the period 1990-2012 (Hong Kong, Macao, Taiwan and Tibet are excluded because of the lack of data). The data of the provincial demographic changes (population size, urban population, working-age population and household size), GDP and the added value of the industrial sector were collected from the China Statistical Yearbook and China Compendium of Statistics. The data on total energy consumption are obtained from the China Energy Statistical Yearbook. The $\mathrm{CO}_{2}$ emissions data were calculated according to the formula provided by the Intergovernmental Panel on Climate Change (IPCC) (2006) (Provided by website: http:// www.ipcc-nggip.iges.or.jp/). The primary energy carbon emission coefficient for coal, petroleum, natural gas, and non-fossil energy are $0.7476,0.5825,0.4435$ and 0 , respectively (ton $C /$ ton stand coal), which are sourced from the Energy Research Institute of Chinese National Development and Reform Commission [52]. To eliminate the influence of price index, the GDP is calculated at a constant price (1990 prices) and the proportion of industry output in GDP is calculated accordingly. Table S4 provides a detailed description of all variables used in this study.

\subsection{Data description}

Table S5 provides summary statistics and correlations, as well as cross-sectional independence (CD) tests among the variables. Both energy consumption and $\mathrm{CO}_{2}$ emissions were positively correlated with population size, the level of urbanisation, the share of the working-age population, per capita GDP and the share of the industrial sector but negatively associated with household size and energy intensity. In addition, the results of the CD test clearly indicated the presence of cross-sectional dependence for all the variables.

Fig. 2 shows the changing rates of the variables, with 1990 as the base year. Almost all the variables were non-stationary, with a continuous uptrend or downtrend during the period. Among these variables, per capita GDP experienced the fastest growth at 7.89 times, followed by energy consumption (3.57 times) and $\mathrm{CO}_{2}$ emissions (3.15 times) from 1990 to 2010. Population size, the share of the working-age population and the industrial sector

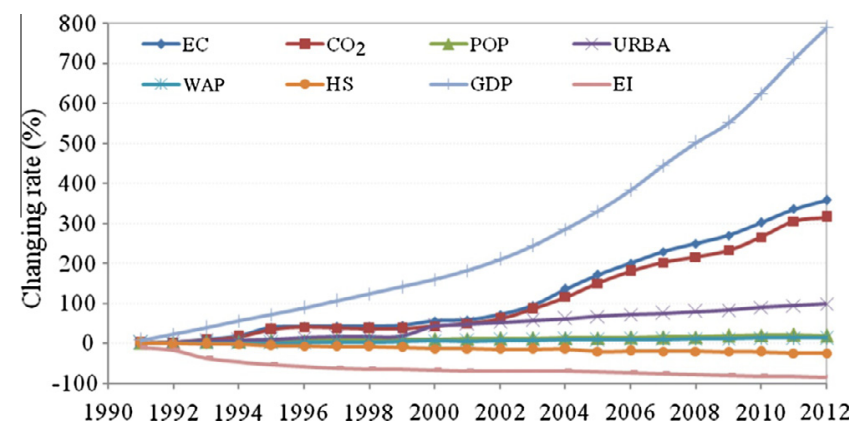

Fig. 2. Changing rate of population, energy consumption and $\mathrm{CO}_{2}$ emissions in China between 1990 and 2012. EC is energy consumption, $\mathrm{CO}_{2}$ is dioxide carbon emissions, POP is population size, URBA is urbanisation level, WAP is share of the working-age population, HS is household size, and EI is energy intensity. increased by $18.58 \%, 12.66 \%$ and $17.51 \%$, respectively. Energy intensity and average household size presented a shrinking trend, with decreases of $84.22 \%$ and $25 \%$, respectively.

Fig. 3 displays the trend variations in demography, energy consumption and $\mathrm{CO}_{2}$ emissions for China's 30 provinces during the 1990-2012. Guangdong province has experienced the fastest growth rate in population, followed by Henan, Shandong, Jiangsu, Hebei and Shanghai (Fig. 3a). Regarding urbanisation level, the growth rate of urbanisation in eastern China was higher than that of the central and western regions (Fig. 3b). The five provinces with the highest growth rates in the working-age population were Guangdong, Fujian, Hainan, Shanghai and Shaanxi provinces, which may be correlated with mass immigration over past two decades (Fig. 3c). The average household size of all provinces exhibited a decreasing trend, with the greatest rate in Fujian, followed by Qinghai, Guangxi, Ningxia and Guangdong provinces (Fig. 3d). China's houses tripled in size between 1978 and 2012 with per capita floor space increasing from 8.1 to $26.5 \mathrm{~m}^{2}$ and from 6.7 to $22.8 \mathrm{~m}^{2}$, in rural and urban China [53]. Low birth rates, late marriage and population migration have contributed to China's shrinking households. China's rapidly growing economy and energy consumption has led to serious environmental problems on both the local and global scales [54]. Both energy consumption and $\mathrm{CO}_{2}$ emissions in all provinces presented an increasing trend, with the greatest rate in Shandong province, followed by Guangdong, Hebei and Jiangsu (Fig. 3e and f). As a result of its abundant domestic stocks of coal, China heavily depends on coal as its primary source of energy [55]. Coal consumption is largely responsible for the high levels of air pollution in China [56]. Additionally, the rapid growth rate of $\mathrm{CO}_{2}$ emissions in the richer eastern region may be the result of rapid increase in capital investment and the rapid growth of urban consumption [57].

\section{Results analysis}

\subsection{Demographic changes and energy consumption}

Table 1 provides estimates for the impact of demographic changes and economic growth on energy consumption for the entire sample and for the three regions. In comparison with the FE model, FD models can address important time-series crosssection issues of nonstationarity and cross-sectional dependence. The diagnostics are good in the FD models: the residuals are stationary, and cross-sectional independence in the residuals either cannot be rejected or is mitigated. As the FD models (models 2, 4,6 and 8 ) are the preferred models, our main interpretations focus only on these models. Most of the estimated coefficients are statistically significant at the $5 \%$ level or lower. The entire panel results suggested that population size, urbanisation level and GDP per capita positively affected energy use, whereas the share of the industrial sector negatively affected energy consumption. The correlations between energy consumption and the changes in proportion of the working-age population as well as household size were positive but statistically insignificant at the $10 \%$ level or higher. The elasticities of energy use to population growth, urbanisation and economic development were $0.26,0.15$ and 0.48 , respectively. This result was consistent with that of Zhang and Lin [15], who found that the elasticity of energy consumption to population, urbanisation and GDP per capita were $0.84,0.41$ and 0.27 , respectively. In addition, a $1 \%$ increase in the share of the industrial sector decreases energy use by $0.03 \%$ in China. Our findings show that the changes in household size and population age structure did not exert a significant impact on energy consumption in China, which may be due to the fact that China is a county dominated by industrial energy use. 


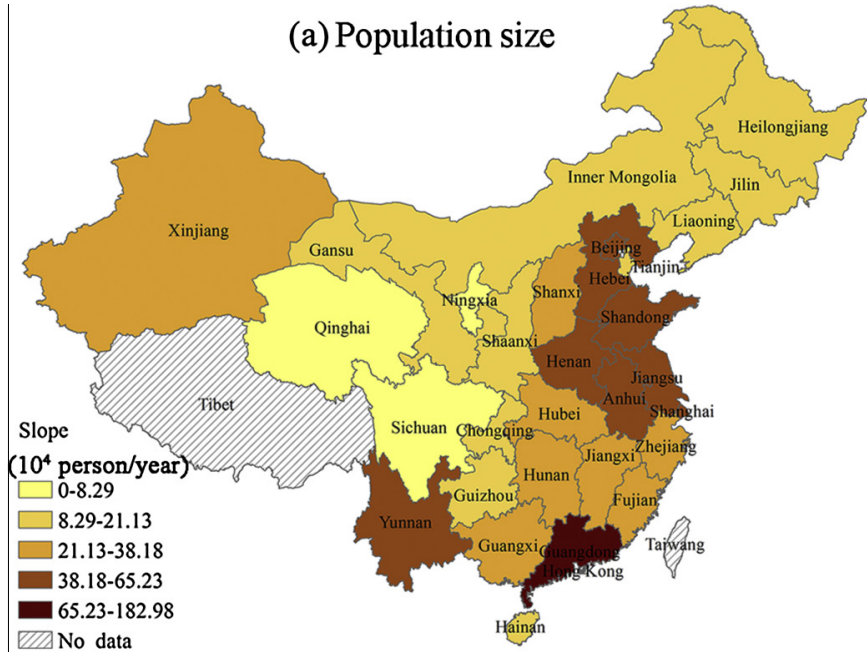

VID No data

\section{(c)Working age population}

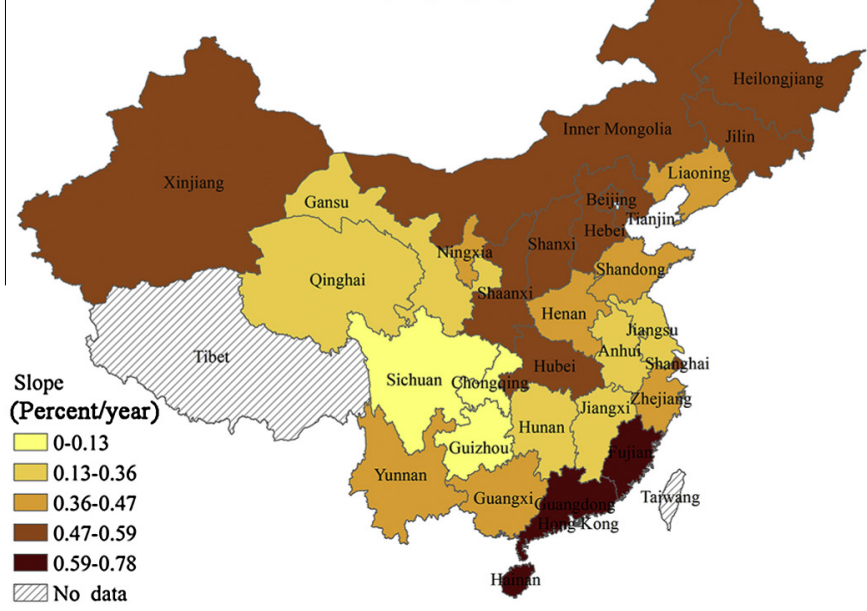

(e) Energy consumption

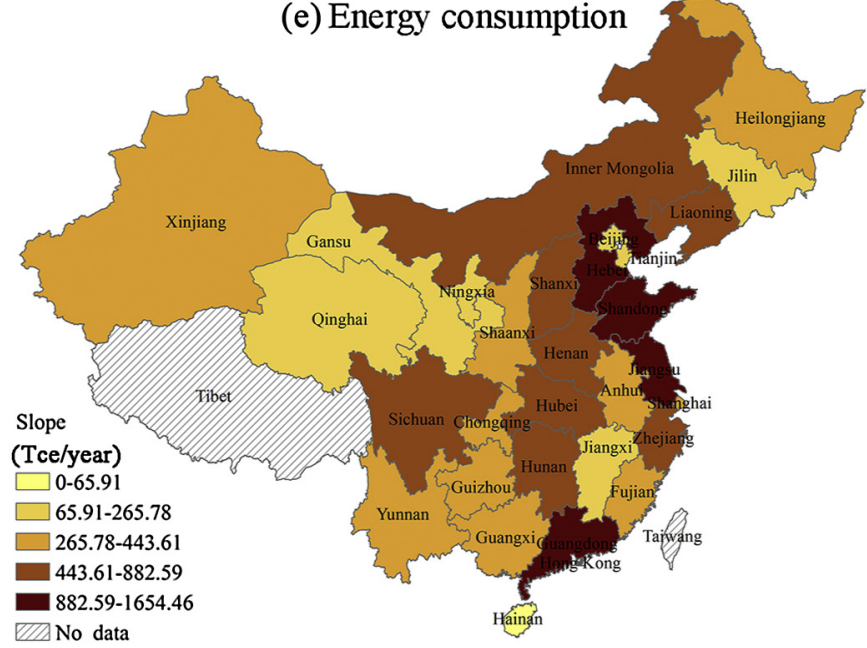

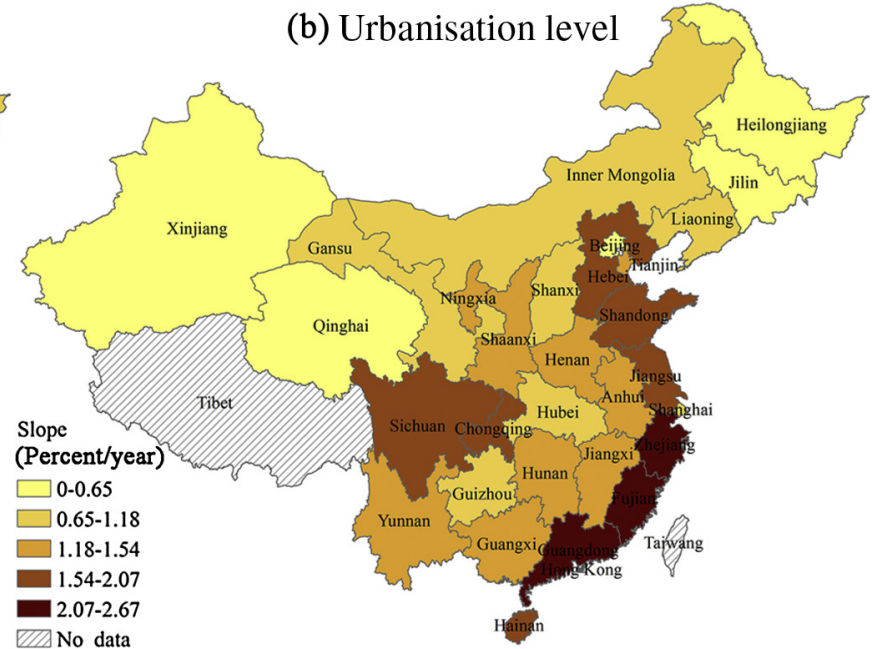

(b) Urbanisation level

(d) Household size
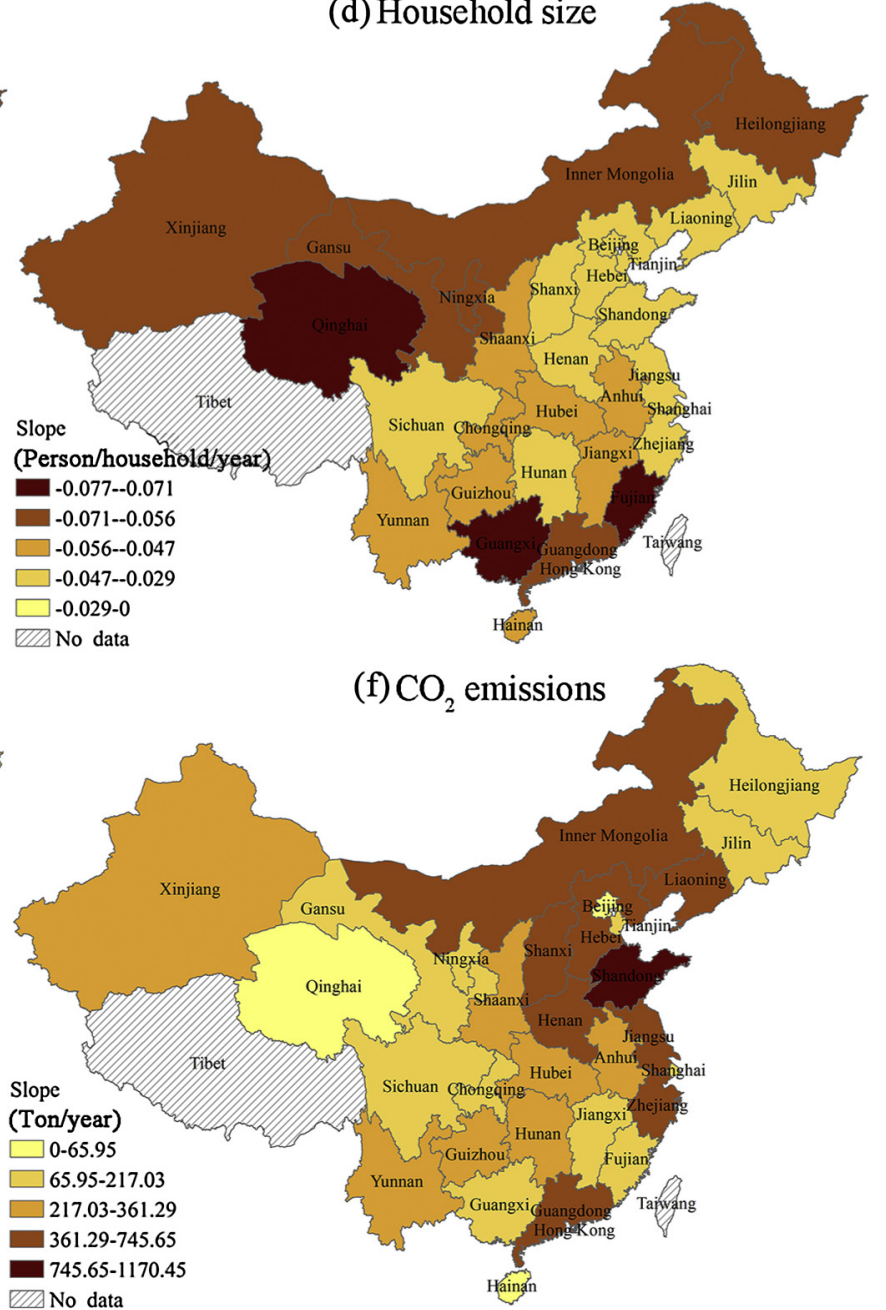

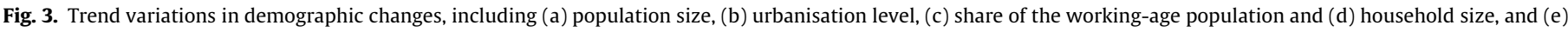
energy consumption and (f) $\mathrm{CO}_{2}$ emissions for China's 30 provinces between 1990 and 2012.

At the regional level, the impact of demographic changes, economic growth and technological advances on energy consumption varied across the regions. Population growth increased energy consumption in the three regions, but their correlation in the central region was statistically insignificant at the $10 \%$ level or higher. Economic growth contributed to the increase in energy use at the regional level. The relationship between urbanisation and energy use in the eastern and central regions was positive and significant, whereas that in the western region was not statistically significant. A $1 \%$ increase in the urbanisation rate increased energy consumption in the eastern and central regions by $0.17 \%$ and $0.16 \%$, respectively. The correlation between the share of the working-age population and energy use in the eastern region was positive but statistically insignificant, whereas the correlation 
Table 1

Estimated results for energy consumption models for China and its three regions.

\begin{tabular}{|c|c|c|c|c|}
\hline \multirow[t]{2}{*}{ Variable } & \multicolumn{2}{|l|}{ The entirety of China } & \multicolumn{2}{|l|}{ Eastern region } \\
\hline & $\mathrm{FE}(1)$ & FD (2) & $\mathrm{FE}(3)$ & $\mathrm{FD}(4)$ \\
\hline Ln (POP) & $1.35^{* * *}[0.701 .99]$ & $0.26^{* *}[-0.120 .64]$ & $0.58^{* * *}[-0.37$ 1.53] & $0.20^{* * *}\left[\begin{array}{lll}-0.48 & 0.88\end{array}\right]$ \\
\hline Ln (URBA) & $0.34^{* * *}\left[\begin{array}{lll}0.14 & 0.54\end{array}\right]$ & $0.15^{* * *}\left[\begin{array}{ll}0.05 & 0.25\end{array}\right]$ & $0.41^{* *}\left[\begin{array}{lll}0.12 & 0.70\end{array}\right]$ & $0.17^{* *}\left[\begin{array}{lll}0.00 & 0.23\end{array}\right]$ \\
\hline Ln (WAP) & $0.54[-0.751 .83]$ & $0.07\left[\begin{array}{lll}-0.34 & 0.49\end{array}\right]$ & $0.60\left[\begin{array}{ll}-1.25 & 2.45\end{array}\right]$ & $0.30[-0.561 .15]$ \\
\hline Ln (HS) & $-0.16\left[\begin{array}{lll}-0.76 & 0.43\end{array}\right]$ & $0.04\left[\begin{array}{lll}-0.15 & 0.23\end{array}\right]$ & $0.39\left[\begin{array}{lll}-0.66 & 1.45\end{array}\right]$ & $0.01\left[\begin{array}{lll}-0.35 & 0.37]\end{array}\right]$ \\
\hline Ln (pGDP) & $0.56^{* * *}\left[\begin{array}{ll}0.21 & 0.89\end{array}\right]$ & $0.48^{* * * *}\left[\begin{array}{lll}0.46 & 0.70\end{array}\right]$ & $0.31^{* *}[-0.020 .63]$ & $0.73^{* * *}\left[\begin{array}{lll}0.32 & 1.13\end{array}\right]$ \\
\hline Ln (INDU) & $0.49^{* * *}\left[\begin{array}{lll}0.28 & 0.71\end{array}\right]$ & $-0.03^{* *}[-0.05]$ & $0.48\left[\begin{array}{lll}0.30 & 0.64\end{array}\right]$ & $-0.03^{* *}[-0.050]$ \\
\hline Constant & $-11.87^{* *}[-20.07-3.66]$ & - & $-5.25\left[\begin{array}{lll}-17.75 & 7.24\end{array}\right]$ & - \\
\hline Province dummies & Yes & - & Yes & - \\
\hline Year dummies & Yes & Yes & Yes & Yes \\
\hline AC test & $\mathrm{F}(1,29)=157.49^{* * *}$ & - & $\mathrm{F}(1,10)=53.31^{* * *}$ & - \\
\hline $\mathrm{CD}(p)$ & $-2.55^{* *}(0.01)$ & $-1.59(0.11)$ & $-2.67^{* *}(0.01)$ & $-0.40(0.69)$ \\
\hline HK test & $x^{2}(30)=1740.80^{* * *}$ & - & $x^{2}(11)=590.15^{* * *}$ & - \\
\hline CIPS & $I(1)$ & $I(0)$ & $I(1)$ & $I(0)$ \\
\hline RMSE & - & 0.080 & - & 0.090 \\
\hline $\mathrm{R}^{2}$ & 0.949 & 0.547 & 0.958 & 0.557 \\
\hline Observations & 690 & 660 & 253 & 242 \\
\hline \multirow[t]{2}{*}{ Variable } & \multicolumn{2}{|l|}{ Central region } & \multicolumn{2}{|l|}{ Western region } \\
\hline & $\mathrm{FE}(5)$ & $\mathrm{FD}(6)$ & $\mathrm{FE}(7)$ & $\mathrm{FD}(8)$ \\
\hline $\operatorname{Ln}(\mathrm{POP})$ & $0.74[-0.501 .99]$ & $0.08\left[\begin{array}{lll}-0.59 & 0.74\end{array}\right]$ & $3.83^{* * *}\left[\begin{array}{ll}2.61 & 5.05\end{array}\right]$ & $0.62^{* * *}\left[\begin{array}{ll}0.25 & 1.51\end{array}\right]$ \\
\hline Ln (URBA) & $0.41^{* *}\left[\begin{array}{ll}0.08 & 0.73\end{array}\right]$ & $0.16^{* *}[-0.040 .37]$ & $0.19\left[\begin{array}{lll}-0.155 & 0.54\end{array}\right]$ & $0.14\left[\begin{array}{lll}-0.04 & 0.33\end{array}\right]$ \\
\hline Ln (WAP) & $0.20[-1.902 .31]$ & $-0.46\left[\begin{array}{ll}-1.16 & 0.24\end{array}\right]$ & $-0.15\left[\begin{array}{lll}-1.76 & 1.45\end{array}\right]$ & $-0.48\left[\begin{array}{ll}-0.81 & 0.72\end{array}\right]$ \\
\hline Ln (HS) & $0.73^{* *}\left[\begin{array}{ll}-0.17 & 1.47\end{array}\right]$ & $0.27^{* *}[-0.030 .56]$ & $-0.89^{* *}[-1.61-0.16]$ & $-0.21\left[\begin{array}{ll}-0.62 & 0.21]\end{array}\right.$ \\
\hline Ln (pGDP) & $0.51^{* * *}\left[\begin{array}{lll}0.14 & 0.88\end{array}\right]$ & $0.44^{* *}\left[\begin{array}{lll}0.02 & 0.85\end{array}\right]$ & $1.19^{* * *}[0.771 .60]$ & $0.31^{* * *}\left[\begin{array}{ll}0.02 & 0.78\end{array}\right]$ \\
\hline Ln (INDU) & $0.48\left[\begin{array}{lll}0.30 & 0.64\end{array}\right]$ & $-0.02\left[\begin{array}{ll}-0.07 & 0.04\end{array}\right]$ & $-0.06\left[\begin{array}{ll}-0.44 & 0.32\end{array}\right]$ & $0.02\left[\begin{array}{lll}-0.08 & 0.14\end{array}\right]$ \\
\hline Constant & $-5.29\left[\begin{array}{lll}-12.33 & 1.74]\end{array}\right.$ & - & $-28.93[-41.36-16.5]$ & - \\
\hline Province dummies & Yes & - & Yes & - \\
\hline Year dummies & Yes & Yes & Yes & Yes \\
\hline AC test & $\mathrm{F}(1,7)=29.85^{* * *}$ & - & $\mathrm{F}(1,10)=99.23^{* * *}$ & - \\
\hline $\mathrm{CD}(p)$ & $-3.12^{* * *}(0.00)$ & $-3.01(0.10)$ & $-3.48^{* * *}(0.00)$ & $-3.09(0.12)$ \\
\hline HK test & $x^{2}(8)=183.92^{* * *}$ & - & $x^{2}(11)=88.69^{* * *}$ & - \\
\hline CIPS & $I(1)$ & $I(0)$ & $I(1)$ & $I(0)$ \\
\hline RMSE & - & 0.050 & - & 0.085 \\
\hline $\mathrm{R}^{2}$ & 0.972 & 0.557 & 0.972 & 0.561 \\
\hline Observations & 184 & 176 & 253 & 242 \\
\hline
\end{tabular}

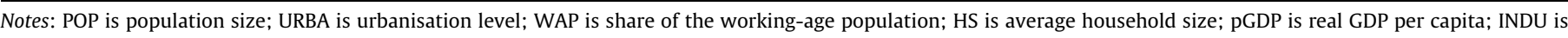

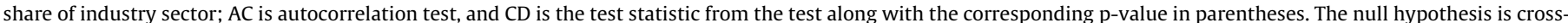

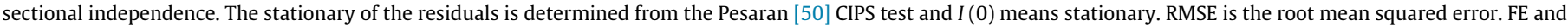
FD are the fix effect and first differenced models, respectively.

${ }^{* *}$ Indicate statistical significance at the 5\% level.

*** Indicate statistical significance at the $1 \%$ level.

in the central and western regions was negative. Shrinking household size significantly increased energy consumption in the central region but the relationship between these variables was not significant in eastern and western China. The share of the industrial sector negatively affected energy consumption in the eastern region, but its effects in both the central and western regions were insignificant at the $10 \%$ level or higher.

\subsection{Demographic changes and $\mathrm{CO}_{2}$ emissions}

Table 2 reports the estimates for the impact of demographic changes and economic growth on aggregate $\mathrm{CO}_{2}$ emissions for the entire sample and for the three regions. Model 10 shows that the elasticities of $\mathrm{CO}_{2}$ emissions to population size, working-age population, GDP per capita and energy intensity were $0.46,0.45$, 0.69 and 0.02 , respectively, indicating that economic development has had a greater environmental impact than population growth in China (Fig. 3). This result was not consistent with some previous assessments at the global level and in OECD countries, where population was shown to have a greater environmental impact than affluence $[8,9,20,43]$. Our results may demonstrate that China's rapid population growth does not necessarily result in the inevitable intensification of environmental pressure. Minx et al. [28] claimed that the structural change in China's economy was one of the main drivers of emissions. China's national socio-economic policies also have a significant impact on its environmental pressure [58]. Furthermore, a $1 \%$ increase in the share of the working-age population increases $\mathrm{CO}_{2}$ emissions by $0.45 \%$, which is far below the results of Zhu and Peng [16], who estimated that the elasticity of the working-age population to emissions was 1.32. Energy intensity had has a mild positive effect on $\mathrm{CO}_{2}$ emissions, whereas the share of the industrial sector negatively affected emissions. The relationship between $\mathrm{CO}_{2}$ emissions and household size was positive but statistically insignificant, which is inconsistent with a previous study showing that shrinking household size lowers emissions in developing countries [13]. The elasticity of urbanisation to $\mathrm{CO}_{2}$ emissions was 0.07 , which was in line with previous studies- although these studies have produced a wide range of urbanisation elasticity estimates (from 0.09 to 0.50 ) in China $[15,16,35,59]$. Furthermore, our estimates also showed that decreasing household size or growing population had a greater impact on $\mathrm{CO}_{2}$ emissions than urbanisation. This result is not supported by Minx et al. [28] who found that urbanisation was more important to China's rapidly growing emissions than other sociodemographic drivers.

The impact of demographic changes and economic growth on $\mathrm{CO}_{2}$ emissions was also heterogeneous across regions (models 12 , 14 and 16). The elasticities of $\mathrm{CO}_{2}$ emissions to population growth in the eastern, central and western regions were $0.31,0.39$ and 0.77 , respectively (Table 2). The estimated population-emission 
Table 2

Estimated results for $\mathrm{CO}_{2}$ emissions models for the whole China and the three regions.

\begin{tabular}{|c|c|c|c|c|}
\hline & \multicolumn{2}{|l|}{ The whole China } & \multicolumn{2}{|l|}{$\underline{\text { Eastern region }}$} \\
\hline & FE (9) & FD (10) & $\mathrm{FE}(11)$ & FD (12) \\
\hline $\operatorname{Ln}(\mathrm{POP})$ & $1.04^{* * *}\left[\begin{array}{ll}0.29 & 1.78\end{array}\right]$ & $0.46^{* *}\left[\begin{array}{ll}0.01 & 0.91\end{array}\right]$ & $0.97^{* *}\left[\begin{array}{ll}0.41 & 2.35\end{array}\right]$ & $0.31^{* *}\left[\begin{array}{lll}0.21 & 1.23\end{array}\right]$ \\
\hline Ln (URBA) & $0.09\left[\begin{array}{ll}-0.15 & 0.33\end{array}\right]$ & $0.07^{* *}\left[\begin{array}{ll}-0.05 & 0.18\end{array}\right]$ & $-0.07^{*}\left[\begin{array}{lll}-0.42 & 0.29\end{array}\right]$ & $0.04^{* *}\left[\begin{array}{lll}-0.19 & 0.26\end{array}\right]$ \\
\hline Ln (WAP) & $1.57^{* *}[-0.093 .23]$ & $0.45^{* *}\left[\begin{array}{lll}-0.04 & 0.94\end{array}\right]$ & $0.07[-1.671 .81]$ & $1.56^{* * *}[0.442 .68]$ \\
\hline $\operatorname{Ln}(\mathrm{HS})$ & $0.33[-0.351 .01]$ & $0.09\left[\begin{array}{ll}-0.13 & 0.32\end{array}\right]$ & $0.18[-0.851 .20]$ & $-0.26\left[\begin{array}{ll}-0.73 & 0.21\end{array}\right]$ \\
\hline Ln (pGDP) & $0.64^{* * *}\left[\begin{array}{lll}0.27 & 1.00\end{array}\right]$ & $0.69^{* * * *}\left[\begin{array}{ll}0.42 & 0.95\end{array}\right]$ & $0.42^{* * *}\left[\begin{array}{lll}0.24 & 1.07\end{array}\right]$ & $0.97^{* * *}\left[\begin{array}{lll}0.42 & 0.95\end{array}\right]$ \\
\hline Ln (INDU) & $0.47^{* * *}\left[\begin{array}{ll}0.12 & 0.82\end{array}\right]$ & $-0.05^{* * *}[-0.08-0.02]$ & $0.59^{* * *}\left[\begin{array}{ll}0.65 & 1.25\end{array}\right]$ & $-0.05^{* * *}\left[\begin{array}{ll}0.42 & 1.5\end{array}\right]$ \\
\hline $\operatorname{Ln}(E I)$ & $0.76^{* * *}\left[\begin{array}{lll}0.47 & 1.03\end{array}\right]$ & $0.02^{* * * *}\left[\begin{array}{lll}0.00 & 0.03\end{array}\right]$ & $1.07^{* * *}[0.861 .28]$ & $0.02^{* *}\left[\begin{array}{ll}-0.03 & 0.06\end{array}\right]$ \\
\hline Constant & $-15.84^{*}[-27.72-3.97]$ & - & $-7.46[-20.025 .08]$ & - \\
\hline Province dummies & Yes & - & Yes & - \\
\hline Year dummies & Yes & Yes & Yes & Yes \\
\hline AC test & $F(1,29)=172.96^{* * *}$ & & $F(1,10)=593.31^{* * *}$ & \\
\hline $\mathrm{CD}(\mathrm{p})$ & $-1.47(0.14)$ & $-0.76(0.44)$ & $-2.00^{* *}(0.04)$ & $-0.37(0.71)$ \\
\hline HK test & $x^{2}(30)=5601.16^{* * *}$ & - & $x^{2}(11)=1160.85^{* * *}$ & \\
\hline CIPS & $I(1)$ & $I(0)$ & $I(1)$ & $I(0)$ \\
\hline RMSE & - & 0.090 & & 0.110 \\
\hline $\mathrm{R}^{2}$ & 0.935 & 0.547 & 0.951 & 0.427 \\
\hline \multirow[t]{3}{*}{ Observations } & 690 & 660 & 253 & 242 \\
\hline & \multicolumn{2}{|l|}{ Central region } & \multicolumn{2}{|l|}{ Western region } \\
\hline & $\mathrm{FE}(13)$ & FD (14) & $\mathrm{FE}(15)$ & FD (16) \\
\hline Ln (POP) & $2.40^{* * *}\left[\begin{array}{ll}1.32 & 3.48\end{array}\right]$ & $0.39^{* *}[0.361 .15]$ & $4.14^{* * *}[1.996 .29]$ & $0.77^{* * *}[0.361 .63]$ \\
\hline Ln (URBA) & $-0.01\left[\begin{array}{ll}-0.31 & 2.89\end{array}\right]$ & $0.16^{* *}\left[\begin{array}{ll}-0.08 & 0.39\end{array}\right]$ & $0.05\left[\begin{array}{ll}-0.31 & 0.41\end{array}\right]$ & $-0.05\left[\begin{array}{ll}-0.22 & 0.13\end{array}\right]$ \\
\hline Ln (WAP) & $1.16[-0.292 .61]$ & $-0.41\left[\begin{array}{lll}-1.20 & 0.38\end{array}\right]$ & $1.25[-0.943 .44]$ & $0.07\left[\begin{array}{ll}-0.68 & 0.83\end{array}\right]$ \\
\hline $\operatorname{Ln}(\mathrm{HS})$ & $0.41[-0.441 .24]$ & $0.43^{* * *}\left[\begin{array}{lll}0.097 & 0.76\end{array}\right]$ & $0.44[-0.851 .73]$ & $0.26\left[\begin{array}{lll}-0.14 & 0.67\end{array}\right]$ \\
\hline Ln (pGDP) & $1.15^{* * * *}[0.441 .85]$ & $0.63^{* * *}[0.161 .10]$ & $1.43^{* * *}\left[\begin{array}{lll}0.95 & 1.92\end{array}\right]$ & $0.40^{* * *}\left[\begin{array}{lll}0.16 & 0.89\end{array}\right]$ \\
\hline Ln (INDU) & $0.18^{* * *}\left[\begin{array}{ll}0.09 & 1.54\end{array}\right]$ & $-0.04^{* * *}\left[\begin{array}{ll}-0.11 & 0.03\end{array}\right]$ & $-0.47^{* *}[-0.960 .29]$ & $-0.01^{* * *}[-0.10 .12]$ \\
\hline $\operatorname{Ln}(\mathrm{EI})$ & $0.71^{* * *}\left[\begin{array}{ll}0.52 & 0.91\end{array}\right]$ & $0.03^{* *}\left[\begin{array}{lll}0.00 & 0.06\end{array}\right]$ & $0.22^{* *}[-0.04 \quad 0.48]$ & $0.03^{* *}\left[\begin{array}{lll}0.00 & 0.05\end{array}\right]$ \\
\hline Constant & $-27.93[-41.20-14.64]$ & - & $-39.84[-60.13-19.56]$ & - \\
\hline Province dummies & Yes & - & Yes & - \\
\hline Year dummies & Yes & Yes & Yes & Yes \\
\hline AC test & $\mathrm{F}(1,7)=104.06^{* * *}$ & - & $\mathrm{F}(1,10)=39.05^{* * *}$ & - \\
\hline $\mathrm{CD}(p)$ & $-3.31^{* * *}(0.00)$ & $-3.01(0.10)$ & $-3.23^{* * * *}(0.00)$ & $-3.03(0.10)$ \\
\hline HK test & $x^{2}(8)=65.66^{* * *}$ & - & $x^{2}(11)=115.25^{* * *}$ & - \\
\hline CIPS & $I(1)$ & $I(0)$ & $I(1)$ & $I(0)$ \\
\hline RMSE & - & 0.060 & - & 0.083 \\
\hline $\mathrm{R}^{2}$ & 0.977 & 0.427 & 0.953 & 0.588 \\
\hline Observations & 184 & 176 & 253 & 242 \\
\hline
\end{tabular}

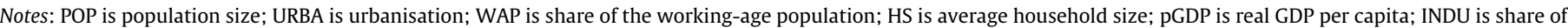

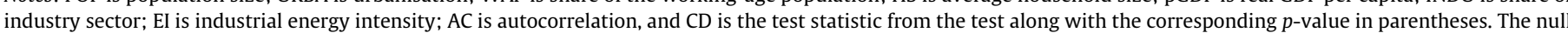

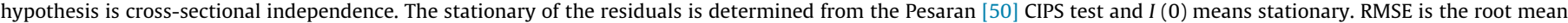
squared error. FE is the fixed effect model and FD is the first differenced model.

* Indicate statistical significance at the $10 \%$ level.

${ }^{* *}$ Indicate statistical significance at the $5 \%$ level.

$* * *$ Indicate statistical significance at the $1 \%$ level.

elasticity in this study was lower than that of previous assessments that estimated the elasticity range from 0.72 to $1.05[15,60]$. In addition, compared with global emission-population elasticities, the impact of population size on carbon emissions in China was considerably lower than the global level or that of both OECD and non-OECD countries, which have resulted in estimations of wide-ranging $\mathrm{CO}_{2}$ emissions elasticities for population from 0.80 to $2.75[8-10,18,39,61,62]$. Urbanisation is closely linked with economic development, both of which inevitably increase energy consumption and $\mathrm{CO}_{2}$ emissions [15,26]. A $1 \%$ increase in the urbanisation level would lead to increase in emissions in the eastern and central regions of $0.04 \%$ and $0.16 \%$, respectively, whereas the coefficient of urbanisation in the western region was statistically insignificant at the level of $10 \%$ or higher. Similar results were obtained by Zhang and Lin [15]. The impact of urbanisation on $\mathrm{CO}_{2}$ emissions in the central region is shown to be greater than that in the eastern and western regions (Fig. 4). The possible mechanism behind this difference is that central China is a major coal production area characterized by an energy-guzzling heavy industrial base, and its energy efficiency is lower than the eastern region $[15,57,63]$. Urbanisation is a complex process that includes not only the shift of the labor force from the agricultural sector in rural areas to the industrial and service sectors in urban areas but also the transfer of products from in-house production to commercial goods, leading to an increase energy use and $\mathrm{CO}_{2}$ emissions $[14,15,26]$. Meanwhile, urbanisation may lead to the accelerated development of the public and transport sectors, requiring additional energy and emitting more $\mathrm{CO}_{2}$. The urbanisation-emission elasticity in the western region was insignificant likely because both urbanisation and economic growth in the region are relatively slow, which indicates that its demand for fossil energy is lower than that of the eastern region due to its abundant water resources, thus exerting relatively little environmental pressure.

Notably, the changes in the working-age population positively affected carbon emissions in the eastern region but the impact in the central and western regions was statistically insignificant at the $10 \%$ level. This result was supported by Fan et al. [11] who found that working-age populations had positive effects in developing countries. China has witnessed the world's greatest ruralurban migration over the last three decades and the provinces of eastern China were the primary destinations of interprovincial migration $[64,65]$. Rural-urban migration has made the dominant contribution to Chinese urban population growth, particularly with regard to the urban working-age population [66]. As shown in 


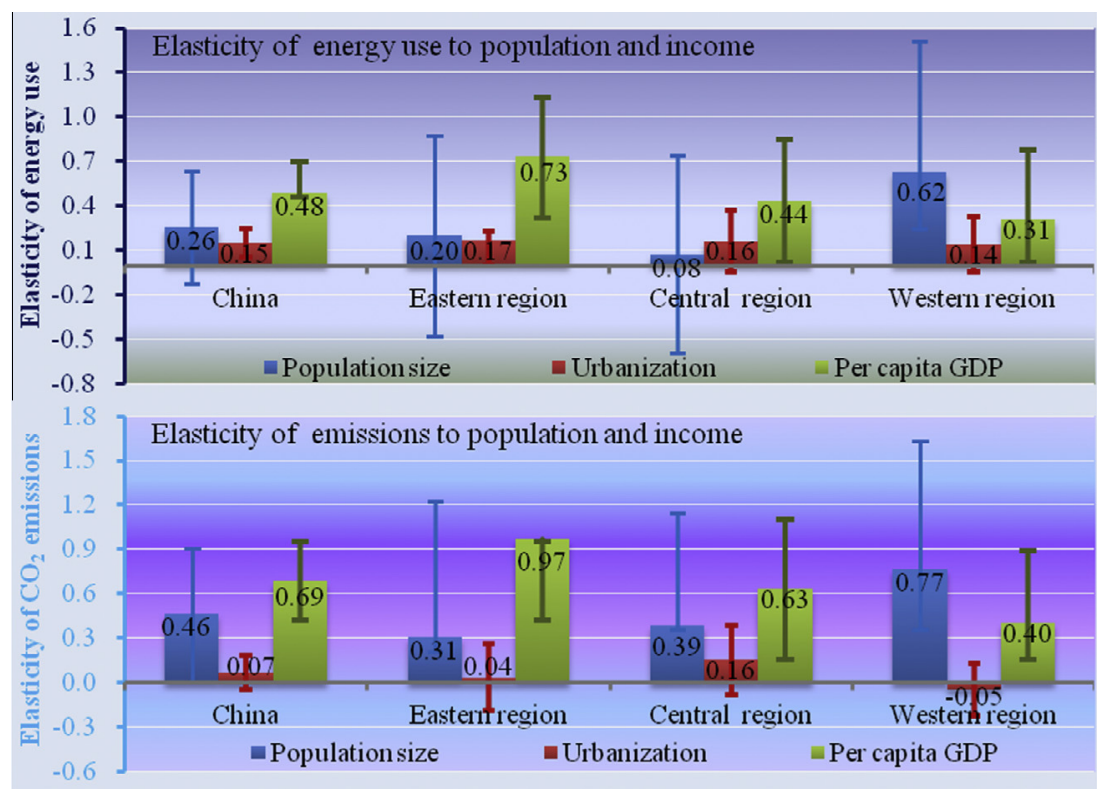

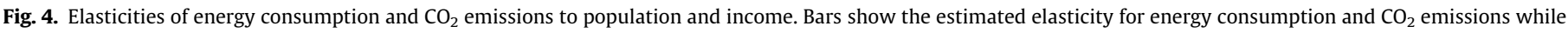
error bars show 95\% confidence interval values obtained using the FD models.

Table S5, the share of the working-age population was closely associated with urbanisation. The agglomeration in the working-age population coupled with the relatively high level of industrialization in the eastern region may require additional energy and more $\mathrm{CO}_{2}$ emissions. In addition, a significant and positive relationship between the changes in household size and carbon emissions was detected only in the central region. The relationship between household size and carbon emissions in the eastern region was negative and positive in the western region but statistically insignificant at the level of $10 \%$ or higher. These results suggested that a shrinking average household size does not necessarily result in decreased carbon emissions in the central and western regionsperhaps because central China is densely populated with moderately developed agriculture and manufacturing industries in which rural residential energy consumption is higher. From 2001 to 2008 , it is reported that the total rural residential energy consumption in China increased from 280.18 million tce to 334.92 million tce, and the corresponding $\mathrm{CO}_{2}$ emissions increased from 152.2 million tons to 283.6 million tons [67]. Total residential energy consumption and $\mathrm{CO}_{2}$ emissions in the central region was higher than in the western and eastern regions [68]. In addition, given a steadily growing population, reduced household sizes would simply lead to an increase in the total number of households, causing the increase in household-based energy consumption demand to exceed that of individual-based demand, thus leading to more $\mathrm{CO}_{2}$ emissions [16]. Cole and Neumayer [8] also noted that the combination of a higher urbanisation rate and lower household size increases $\mathrm{CO}_{2}$ emissions because of the typically more pollution-intensive behavioural patterns of urban populations, particularly in developing countries.

The effect of economic growth on $\mathrm{CO}_{2}$ emissions varied different across regions [69]. The elasticity of GDP per capita to emissions in the eastern region was 0.97 , which was greater than in the central $(0.63)$ and western $(0.40)$ regions. The carbon emissions elasticity of income was larger than the elasticity of population at both the national and regional levels - except for the western region (Fig. 3). This result indicated that economic growth may be the dominant driving force behind the increased carbon emissions rather than population in China over the past two decades, which might have resulted from two main reasons. Rapid economic growth requires the consumption of more energy resources than population. China's economic growth rate has neared and even exceeded the natural population growth rate, particularly since 2000 [70]. Our findings were not consistent with those of some previous studies that have shown that population has a greater environmental impact than affluence $[8,9,20,43]$. In addition, as with the entire sample, the changes in the share of industrial sectors in GDP had a slightly negative impact on emissions at the regional level, with negative elasticity estimates ranging from 0.01 to 0.05 . The elasticities of $\mathrm{CO}_{2}$ emissions to energy intensity in the eastern, central and western regions were $0.02,0.03$ and 0.03 , respectively, indicating that energy intensity had only a minor positive effect on carbon emissions at the regional level. Notably, most estimated emissions elasticities for population and income in this study are less than the results from previous estimates for China possible because additional demographic variables (i.e., age structure and household size) were added and because this study considered the stationarity of the variables.

\section{Discussion}

China is still a developing country, and is undergoing a rapid urban-rural development transformation [17,25,71-73]. The rapid rural-urban transformation has caused excessive population concentration, consumption of resources and environmental deterioration. Identifying the key factors affecting on energy consumption and carbon emissions could provide benefic references for the national strategy for urbanisation and environmental planning [17]. There exist complex linkages among the demographic change, economic growth, resource consumption and environmental pollution. Previous studies have shown that population and economic growth contribute to the increase of resource consumption and emit more pollutant emissions [15]. However, inconsistent conclusions on the extent what population and economic growth affect the environment have been concluded. More importantly, most of environmental impact assessments have either omitted demographic changes, such as household size, population emigration and age structure or treated them as a fragmentary or overly simplified manner [13]. Thus, this study tried to address these issues and provides a full acknowledge on the relationship between population, economic change and the environment. 
China's extensive modes of economic growth over the past decades have aroused many urban curses of crowding, air, and soil and water pollution. Sustainable development of population, resources, economy and environment needs to control population size and migration as well as economic growth rate reasonably. Compared with demographic change, economic growth was identified as the main factors impact the environment in China. Moreover, we observed that the impact of human activities on the environment varies across regions, which is agreement with many previous studies [15,17]. Our results will be of special interest to policy makers and urban planners in China. Considering the regional differences demographic and economic change on energy and $\mathrm{CO}_{2}$ emissions, mitigation strategies should focus on controlling the scale of urbanisation development, optimizing the industrial structures and improving the energy efficiency in eastern and central China. Formulating specific region-oriented energy saving and emission reduction strategies may provide a more practical and effective approach to achieving sustainable development in China.

As a developing country with a large population, China should learn the valuable experience from the developed regions in the coordination of population and economy growth, resource depletion and environment protection [74-76]. The theory of organic decentralization laid a solid foundation for the evacuated population and industry decisions in the developed countries [77]. Furthermore, China also should summary its successful experience and measures in environmental pollution control, such as the 2008 Olympic Games and 2014 APEC Summit [56,78]. Facing the new normal of economic development, China's new-type urbanisation strategy has proposed the people-oriented development goals, which provides new requirements and challenges for realizing the sustainable development of population, resources and the environment [26].

\section{Conclusions and policy implications}

We reassessed the impact of population and income on energy consumption and carbon emissions in China at the national and regional levels and found that most previous studies regarding emission-population/income elasticity for China have produced wide-ranging estimations. Population and economic growth increased energy consumption and carbon emissions in China. The emissions-income elasticity in the eastern region was greater than that in the central and western regions, indicating that rapid income growth exerts a greater pressure than population on the environment. It is necessary to change the former patterns of high pollution and energy use associated with economic growth to reduce carbon dioxide emissions.

Urbanisation positively affected energy consumption and $\mathrm{CO}_{2}$ emissions in China, particularly in China's eastern and central regions, whereas that effect in the western region was statistically insignificant. The effects of other demographic factors (i.e., working-age population and household size) to energy consumption and carbon emissions were also heterogeneous across regions. The relationship between changes in the working-age population or household size and energy consumption was statistically insignificant. The change in share in the working-age population positively affected $\mathrm{CO}_{2}$ emissions in China and its eastern region. The proportion of the working-age population in China peaked in 2010, and this aging workforce will be the major characteristic of China's age structure [14,24]. The country's demographic dividend is declining. Reductions in the working-age population will likely produce an alleviation-dominant impact on carbon emissions in the future, particularly in central and western China. Furthermore, shrinking household size did not reduce residential energy consumption and consequent carbon emissions, indicating that improving residential energy efficiency may be an important way to cut emissions in China. In addition, the changes in the industrial sector's share of GDP had a negative impact on energy consumption and carbon emissions in China, suggesting that technological advances would help reduce the environmental pressure. Further improving energy efficiency and changing the economic structure and growth patterns will likely positively contribute to reduce global environmental pressures [69].

Economic growth was identified as the biggest contributor to environmental pressure in China, followed by population size. China's further economic and population growth will likely require additional energy resources and will result in more emissions [15-17]. In recent years, China's economy has entered a "new normal", an era of relatively slower growth. The country should seize the opportunity to take measures to control the rapid pace of urbanisation, to develop more sustainable infrastructure systems, and to improve energy efficiency as well as upgrade its industrial structure.

\section{Acknowledgments}

The work has been financially supported by the National Natural Science Foundation of China (Grant Nos. 41130748 and 41471143), the Major Program of National Social Foundation of China (Grant No. 15ZDA021) and the Certificate of China Postdoctoral Science Foundation Grant (Grant No. 2016M591105). Cordial thanks should give to two helpful and constructive reviewers whose comments greatly improved our manuscript, as did the comments and encouragements of the Editor-in-Chief (Professor J. Yan).

\section{Appendix A. Supplementary material}

Supplementary data associated with this article can be found, in the online version, at http://dx.doi.org/10.1016/j.apenergy.2016. 08.035 .

\section{References}

[1] Intergovernmental Panel on Climate Change (IPCC). Climate Change 2014: Synthesis Report. In: Core Writing Team, Pachauri PK, Meyer LA, editors. Contribution of working groups I, II and III to the fifth assessment report of the IPCC. Geneva, Switzerland: IPCC; 2014. p. 151.

[2] Sumabat AK, Lopez NS, Yu KD, Hao H, Li R, Geng Y, et al. Decomposition analysis of Philippine $\mathrm{CO}_{2}$ emissions from fuel combustion and electricity generation. Appl Energy 2016;164:795-804.

[3] Guan D, Hubacek K, Weber CL, Peters GP, Reiner DM. The drivers of Chinese $\mathrm{CO}_{2}$ emissions from 1980 to 2030. Glob Environ Change 2008;18(4):626-34.

[4] Feng K, Davis SJ, Sun L, Hubacek K. Drivers of the US $\mathrm{CO}_{2}$ emissions 1997-2013. Nat Commun 2015;6:7714.

[5] Liddle B. What are the carbon emissions elasticities for income and population? Bridging STIRPAT and EKC via robust heterogeneous panel estimates. Glob Environ Chang 2015;31:62-73.

[6] O’Neill BC, Liddle B, Jiang L, Smith KR, Pachauri S, Dalton M, et al. Demographic change and carbon dioxide emissions. Lancet 2012;380:157-64.

[7] York R, Rosa EA, Dietz T. STIRPAT, IPAT and ImPACT: analytic tools for unpacking the driving forces of environmental impacts. Ecol Econ 2003;46 (3):351-65.

[8] Cole MA, Neumayer E. Examining the impact of demographic factors on air pollution. Popul Environ 2004;26(1):5-21.

[9] Shi A. The impact of population pressure on global carbon dioxide emissions, 1975-1996: evidence from pooled cross-country data. Ecol Econ 2003;44 (1):29-42.

[10] Poumanyvong P, Kaneko S. Does urbanization lead to less energy use and lower $\mathrm{CO}_{2}$ emissions? A cross-country analysis. Ecol Econ 2010;70(2):434-44.

[11] Fan Y, Liu LC, Wu G, Wei Y. Analyzing impact factors of $\mathrm{CO}_{2}$ emissions using the STIRPAT model. Environ Impact Assess Rev 2006;26(4):377-95.

[12] Martinez-Zarzoso I, Maruotti A. The impact of urbanization on $\mathrm{CO}_{2}$ emissions: evidence from developing countries. Ecol Econ 2011;70(7):1344-53.

[13] O’Neill BC, Dalton M, Fuchs R, Jiang L, Pachauri S, Zigova K. Global demographic trends and future carbon emissions. P Natl Acad Sci USA 2010;107 (41):17521-6. 
[14] Liddle B. Impact of population, age structure, and urbanization on carbon emissions/energy consumption: evidence from macro-level, cross-country analysis. Popul Environ 2014;35:286-304.

[15] Zhang C, Lin Y. Panel estimation for urbanization, energy consumption and $\mathrm{CO}_{2}$ emissions: a regional analysis in China. Energy Pol 2012;49:488-98.

[16] Zhu Q Peng X. The impacts of population change on carbon emissions in China during 1978-2008. Environ Impact Asses Rev 2012;36:1-8.

[17] Zhou Y, Liu Y, Wu W, Li Y. Effects of rural-urban development transformation on energy consumption and $\mathrm{CO}_{2}$ emissions: a regional analysis in China. Renew Sust Energ Rev 2015;52:863-75.

[18] Knight K, Rosa E, Schor J. Could working less reduce pressures on the environment? A cross-national panel analysis of OECD countries, 1970-2007. Glob Environ Chang 2013;23:691-700.

[19] Chen H, Jia B, Lau SSY. Sustainable urban form for Chinese compact cities: challenges of a rapid urbanized economy. Habitat Int 2008;32:28-40.

[20] Liddle B, Lung S. Age-structure, urbanization, and climate change in developed countries: revisiting STIRPAT fore disaggregated population and consumption-related environmental impacts. Popul Environ 2010;31:317-43.

[21] Sharma SS. Determinants of carbon dioxide emissions: empirical evidence from 69 countries. Appl Energy 2011;88(1):376-82.

[22] Ponce de Leon Barido D, Marshall JD. Relationship between urbanization and $\mathrm{CO}_{2}$ emissions depends on income level and policy. Environ Sci Technol 2014;48(7):3632-9.

[23] Jiang L, Hardee K. How do recent population trends matter to climate change? Popul Res Pol Rev 2011;30(2):287-312.

[24] Peng X. China's demographic history and future challenges. Science 2011;333 (6042):581-7.

[25] Liu Y, Lu S, Chen Y. Spatio-temporal changes of urban-rural equalized development patterns in China and its driving factors. J Rural Stud 2013;32:320-30.

[26] Bai X, Shi P, Liu Y. Realizing China's urban dream. Nature 2014;509:158-60.

[27] Liu Y, Zhou Y, Wu W. Assessing the impact of population, income and technology on energy consumption and industrial pollutant emissions in China. Appl Energy 2015;155:904-17.

[28] Minx JC, Baiocchi G, Peters GP, Weber CL, Guan D, Hubacek K. A “carbonizing dragon": China's fast growing $\mathrm{CO}_{2}$ emissions revisited. Environ Sci Technol 2011;45(21):9144-53.

[29] Guan D, Liu Z, Geng Y, Lindner S, Hubacek K. The gigatonne gap in China's carbon dioxide inventories. Nat Clim Change 2012;2(9):672-5.

[30] International Energy Agency (IEA). Key world energy statistics international energy agency. Paris: Statistics Division; 2012.

[31] Liu Z, Guan D, Crawford-Brown D, Zhang Q, Liu J. Energy policy: a low-carbon road map for China. Nature 2013;500(7461):143-5.

[32] Cong R, Wei Y. Potential impact of (CET) carbon emissions trading on China's power sector: a perspective from different allowance allocation options. Energy 2010;35(9):3921-31.

[33] Wang Z, Zeng $H$, Wei $Y$, Zhang $Y$. Regional total factor energy efficiency: an empirical analysis of industrial sector in China. Appl Energy 2012;97:115-23.

[34] Wang C, Liao H, Pan S, Zhao L, Wei Y. The fluctuations of China's energy intensity: biased technical change. Appl Energy 2014;135:407-14.

[35] Wang P, Wu W, Zhu B, Wei Y. Examining the impact factors of energy-related $\mathrm{CO}_{2}$ emissions using the STIRPAT model in Guangdong Province, China. Appl Energy 2013;106:65-71.

[36] Wang Y, Zhao T. Impacts of energy-related $\mathrm{CO}_{2}$ emissions: evidence from under developed, developing and highly developed regions in China. Ecol Indic 2015;50:186-95.

[37] Fumo N, Biswas MAR. Regression analysis for prediction of residential energy consumption. Renew Sust Energ Rev 2016;47:332-43.

[38] Fujimi T, Kajitani Y, Chang SE. Effective and persistent changes in household energy-saving behaviors: evidence from post-tsunami Japan. Appl Energy 2016;167:93-106.

[39] York R. Demographic trends and energy consumption in European Union Nations, 1960-2025. Soc Sci Res 2007;36:855-72.

[40] Hasanov FJ, Bulut C, Suleymanov E. Do population age groups matter in the energy use of the oil-exporting countries? Econ Model 2016;54:82-99.

[41] Menyah K, Wolde-Rufael Y. Energy consumption, pollutant emissions and economic growth in South Africa. Energ Econ 2010;32(6):1374-82.

[42] Ehrlich PR, Holdren JP. Impact of population growth. Science 1971;191 (3977):1212-7.

[43] Dietz T, Rosa EA. Rethinking the environmental impacts of population, affluence and technology. Hum Ecol Rev 1994;1:277-300.

[44] Cong R, Shen S. Relationships among energy price shocks, stock market, and the macroeconomy: evidence from China. Sci World J 2013;2013:1-9.

[45] Cong R, Wei Y, Jiao L. Relationships between oil price shocks and stock market: an empirical analysis from China. Energy Pol 2008;36(9):3544-53.
[46] Cong R, Wei Y. Experimental comparison of impact of auction format on carbon allowance market. Renew Sust Energ Rev 2012;16(6):4148-56.

[47] Pesaran M. A simple panel unit root test in the presence of cross-section dependence. J Appl Econom 2007;22:265-312.

[48] Wooldridge JM. Econometric analysis of cross section and panel data. Cambridge, Massachusetts: The MIT Press; 2002.

[49] Greene WH. Econometric analysis. Upper Saddle River, New Jersey: Prentice Hall; 2000.

[50] Pesaran MH. General diagnostic tests for cross section dependence in panels. CESifo working paper; 2004.

[51] Zhang C, Zhao W. Panel estimation for income inequality and $\mathrm{CO}_{2}$ emissions: a regional analysis in China. Appl Energy 2014;136:382-92.

[52] Meng $\mathrm{M}$, Niu D. Modeling $\mathrm{CO}_{2}$ emissions from fossil fuel combustion using the logistic equation. Energy 2011;36:3355-9.

[53] Liu JG, Diamond J. China's environment in a globalizing world. Nature 2005;435(7046):1179-86.

[54] Peters GP, Weber CL, Guan D, Hubacek K. China's growing $\mathrm{CO}_{2}$ emissions a race between increasing consumption and efficiency gains. Environ Sci Technol 2007;41(17):5939-44.

[55] Crompton P, Wu Y. Energy consumption in China: past trends and future directions. Energ Econ 2005;27(1):195-208.

[56] Fu B. Blue skies for China. Science 2008;321:611.

[57] Zhang H, Lahr ML. China's energy consumption change from 1987 to 2007: a multi-regional structural decomposition analysis. Energy Pol 2014;67:682-93.

[58] Liang S, Liu Z, Carwford-Brown D, Wang Y, Xu M. Decoupling analysis and socioeconomic drivers of environmental pressure in China. Environ Sci Technol 2014;48(2):1103-13.

[59] Xu B, Lin B. How industrialization and urbanization process impacts on $\mathrm{CO}_{2}$ emissions in China: evidence from nonparametric additive regression models. Energy Econ 2015;48:188-202.

[60] Li H, Mu H, Zhang M, Li N. Analysis of regional difference on impact factors of China's energy-related $\mathrm{CO}_{2}$ emissions. Energy 2012;39(12):319-26.

[61] Liddle B. Consumption-driven environmental impact and age-structure change in OECD countries: a cointegration-STIRPAT analysis. Demogr Res 2011;24:749-70.

[62] Sadorsky P. The effect of urbanization on $\mathrm{CO}_{2}$ emissions in emerging countries. Energy Econ 2014;41:147-53.

[63] Wang Z, Yin F, Zhang Y, Li N. An empirical research on the influencing factors of regional $\mathrm{CO}_{2}$ emissions: evidence from Beijing city, China. Appl Energy 2012;100:277-84.

[64] Fan CC. Interprovincial migration, population redistribution, and regional development in China: 1990 and 2000 census comparisons. Prof Geogr 2005;57(2):295-311.

[65] Chan KW. Migration and development in China: trends, geography and current issues. Migr Dev 2012;1(2):187-205.

[66] Zhang K, Song S. Rural-urban migration and urbanization in China: evidence from time-series and cross-section analyses. China Econ Rev 2003;14 (4):386-400.

[67] Yao C, Chen C, Li M. Analysis of rural residential energy consumption and corresponding carbon emissions in China. Energy Pol 2012;41:445-50.

[68] Zhu D, Tao S, Wang R, Shen H, Huang Y, Shen G, et al. Temporal and spatial trends of residential energy consumption and air pollutant emissions in China. Appl Energy 2013;106:17-24.

[69] Zhang $\mathrm{C}$, Nian J. Panel estimation for transport sector $\mathrm{CO}_{2}$ emissions and its affecting factors: a regional analysis in China. Energy Pol 2013;63:918-26.

[70] National Bureau of Statistics of the People's Republic of China (NBS). China statistical yearbook 2013. Beijing: China Statistical Press; 2013.

[71] McGee TG. Managing the rural-urban transformation in East Asia in the 21st century. Sustain Sci 2008;3:155-67.

[72] Ma LJC. Urban transformation in China, 1949-2000: a review and research agenda. Environ Plann A 2002;34:1545-69.

[73] Long H, Zou J, Liu Y. Analysis of rural transformation development in China since the turn of the new millennium. Appl Geog 2011;31(3):1094-105.

[74] da Silveira AR, Richards KS. The link between polycentrism and adaptive capacity in river basin governance systems: insights from the river Rhine and the Zhujiang (Pearl River) basin. Ann Assoc Am Geogr 2013;103(2):319-29.

[75] Zhou X, Zhang J, Li J. Industrial structural transformation and carbon dioxide emissions in China. Energy Pol 2013;57:43-51.

[76] Klein S, Worch E, Knepper TP. Occurrence and spatial distribution of microplastics in river shore sediments of the Rhine-Main area in Germany. Environ Sci Technol 2015;49(10):6070-6.

[77] Shi Y, Chen Y. New city planning and construction in Shanghai: retrospective and prospective. Int J Urban Sci 2015:1-24.

[78] Liu Y, Li Y, Chen C. Pollution: build on success in China. Nature 2015;517:145. 